\title{
An Insight into the Ubiquity of Root Resorption in Orthodontics- A Review
}

\author{
Sunegha Kundal \\ Department of Orthodontics and Dentofacial Orthopaedics, PDM Dental College and Research Institute, Bahadurgarh, Haryana, India \\ Email address: \\ suneghakundal@gmail.com \\ To cite this article: \\ Sunegha Kundal. An Insight into the Ubiquity of Root Resorption in Orthodontics- A Review. International Journal of Dental Medicine. \\ Vol. 5, No. 1, 2019, pp. 29-34. doi: 10.11648/j.ijdm.20190501.15
}

Received: September 21, 2018; Accepted: October 16, 2018; Published: May 30, 2019

\begin{abstract}
Root resorption is a common iatrogenic consequence of orthodontic treatment, although it can also be seen in the absence of orthodontic treatment. It may occur at any time during orthodontic treatment and compromise prognosis of the tooth involved and also the stability of treatment results. Orthodontics is the only branch which actually uses the inflammatory process as a tool for solving esthetic and functional problems. Therefore, every orthodontist should know the risk factors of root resorption involved in the process and plan treatment with an aim to reduce its possibility. The severity and degree of root resorption related with orthodontic treatment are multifactorial, involving environmental factors and host factors. A proper medical history, an assessment of predisposing factors, radiographic evaluation of alterations in root morphology and careful planning and execution of orthodontic mechanics may reduce the incidence of root resorption. The current review is aimed at providing clinicians and academics with an insight into the mechanical and biological aspects in the process of root resorption, the methods of identification during its early stages and intervention at the right time to reduce its severity.
\end{abstract}

Keywords: Heavy Orthodontic Forces, Orthodontics, Root Resorption

\section{Introduction}

Root resorption is the undesirable but common sequelae of orthodontic mechanotherapeutics. It has been a concern to clinicians and patients since 1914, when it was first reported by Ottolengui. [1] The problem was investigated comprehensively by Ketcham, who published landmark articles in 1927. [2, 3] In 1929, Ketcham [4] demonstrated with radiographic evidence, the differences between root shape before and after orthodontic treatment. This was followed by a wide range of histological, clinical and physiologic research on root resorption and orthodontic treatment.

It has been shown that root resorption can appear during or after orthodontic treatment and compromise the stability of the treatment results and longevity of the tooth. Recent research has focused more on a cause and effect relationship as well as possible preventive treatment options for this unwelcome event. Furthermore, research has highlighted the genetic as well as molecular aspects of the process and helped clinicians determine who might be susceptible.

The most common type of root resorption occurring due to orthodontic treatment is external apical root resorption [EARR] that results in permanent loss of tooth structure from root apex. The literature shows that patients undergoing orthodontic treatment are more prone to have severe EARR. [5-8] However, this is not the only factor responsible for EARR but the effect of orthodontic treatment can be a major factor. [6,9] Hence, it is important to understand the role of orthodontics in the occurrence of EARR. Major knowledge derived from high-quality research will help reduce these adverse effects.

\section{Pathophysiology}

The process of root resorption is closely associated with the injury and necrosis of PDL. During the movement of a tooth, areas of compression (where osteoclasts are in action inducing bone resorption) and areas of tension (where osteoblasts are active inducing bone deposition) are formed. Hence, a tooth moves in the direction of bone resorption. It is considered that the heavy forces of orthodontic treatment and hyalinization of periodontal tissues induced by increased activity of the cementoclasts and osteoclasts result in the 
occurrence of root resorption. When heavy orthodontic forces are applied, a hyaline zone is formed around the tooth root because of the resulting imbalance between the process of bone resorption and deposition and thus, tooth movement stops. This hyaline zone is removed by mononucleus cells and multi-nuclei giant cells along with regeneration of periodontal ligament and the tooth starts to move again. While removal of the hyaline zone, an outer tooth root surface consisting of layer of cementoblasts may be damaged which leads to the loss of protective characteristics of cementum contributing to cementoclasts/osteoclasts resorbing the areas of root and thus exposing the underlying dense mineralized cementum. [10-12] Hence, it is possible that a force occurring during orthodontic treatment may damage outer root surface. The tooth root surface under the hyaline zone resorbs after a few days, when the repair process is already occurring in the periphery. In the literature data, it is stated that the resorption process is completed just after removal of the hyaline zone and when the orthodontic force decreases. $[10,13]$

Radiographically, resorption is mostly observed in apical region of the root because the apical root third is covered with cellular cementum, which relies on active cells and supporting vasculature, the loss of which renders the area vulnerable to trauma and cell injury-related reactions.[14] It is reported that blood vessels occupy $47 \%$ of the PDL space in the apical region, compared with $4 \%$ at the cervical end of theroot. [15] In addition, there is a decrease in the hardness and elastic modulus of the cementum, from the cervical to the apical region, making the apical areas prone to resorption. [16] Furthermore, the fulcrum of tooth movement (centre of rotation) is occlusal to the apical half of the root during tipping movements. This, along with the differences in the direction of the periodontal fibres likely results in increased trauma to the apical and middle thirds of the root. [17]

\section{Classification}

\subsection{According to Shafer, Hine and Levy}

According to Shafer, Hine and Levy resorption of root occurs in many circumstances other than the normal process associated with shedding of deciduous teeth.[18] Resorption of root may occur either on the external surface or internal surface of the root, thus classified as:

(1)External root resorption.

(2)Internal root resorption.

\subsection{Andreasen}

Andreasen gave a modified system classification which provides a more detailed description of the differing presentations of root resorption. [19] Root resorption has been broadly classified as:-

(1)External root resorption-

(a) External surface resorption,

(b)External inflammatory resorption,

(c) External cervical resorption
(2)Internal root resorption-

(a)Internal surface resorption

(b)Internal inflammatory resorption

(c)Internal replacement resorption

\subsection{According to Proffit}

According to Proffit shortening of roots after orthodontic treatment occurs in three distinct forms. [20] These forms must be distinguished when the etiology of resorption is considered:

(1)Moderate Generalized Root Resorption

(2)Severe Generalized Root Resorption

(3)Severe Localized Root Resorption

\subsection{Fuss Z, Tsesis I and Lin $S$}

Fuss Z, Tsesis I and Lin S said that the classical classification of root resorption following traumatic injuries i.e. replacement and inflammatory resorption are related to completely different aetiologies. So it is essential to develop a new, clinically related classification and the various types of root resorption should be identified according to the stimulating factors, which can be as follows [21]:

(1)Pulpal infection root resorption.

(2)Periodontal infection root resorption.

(3)Orthodontic pressure root resorption.

(4)Impacted tooth or tumour pressure root resorption.

(5)Ankylotic root resorption.

\section{Grading of Apical Root Resorption}

\subsection{Robert W. De Shields (1969)}

Robert W. De Shields (1969) using intraoral periapical Xrays has described the following grading system for apical root resorption [22]:

Grade 1-Possible resorption

Grade 2- Definite resorption- The apical outline was definitely irregular but the root was not shortened or blunted.

Grade 3-Mild apical blunting- The reduction in root length was less than $3 \mathrm{~mm}$.

Grade 4- Moderate apical blunting- Resorption more than $3 \mathrm{~mm}$ but less than $1 / 3^{\text {rd }}$ the root length.

Grade 5- Severe blunting- More than $1 / 3^{\text {rd }}$ of the original root length was lost.

\subsection{Malmgren $O$ et al (1982)}

Malmgren $\mathrm{O}$ et al (1982) described root resorption index for quantitative assessment of root resorption [23] (Figure 1)

Grade 1-Normal root length only displaying irregular root contour- Mild resorption

Grade 2- Root resorption apically, amounting to less than 2 $\mathrm{mm}$ - Moderate resorption.

Grade 3- Root resorption apically, from $2 \mathrm{~mm}$ to one third of the original root length- Severe resorption.

Grade 4- Root resorption exceeding one third of the original root length-Extreme resorption. 
Later, Zero degree was added to this index, as proposed by Levander et al, [24] in order to point out unaltered teeth in the root apex.

\subsection{David N. Remington et al (1989)}

David N. Remington et al (1989) described the following grading scale for apical root resorption as [25]:

Grade 0- Normal apical contour, same length as pretreatment.

Grade 1- Apical irregularity, same length as pre-treatment.

Grade 2- Apical root resorption of less than $2 \mathrm{~mm}$.

Grade 3- Apical root resorption more than $2 \mathrm{~mm}$, less than one third of original root length.

Grade 4- Apical root resorption more than one third of original root length.

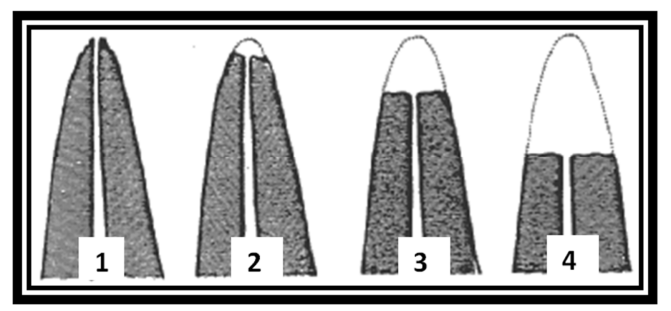

Figure 1. Grading scale for apical root resorption according to Malmgren $O$ et al.

\section{Risk Factors for Root Resorption}

Naphtali Brezniak, Atalia Wasserstein (1993) have described the following factors responsible for Root Resorption: [1, 26]

(1)Biologic Factors: -

1) Genetics

2) Systemic factors
3) Nutrition

4) Chronologic Age

5) Dental age

6) Gender

7) The presence of root resorption before orthodontic treatment

8) Habits

9) Tooth structure

10) Previously traumatized teeth

11) Endodontically treated teeth

12) Alveolar bone density

13) Types of malocclusion

14) Specific tooth vulnerability to root resorption

(2)Mechanical Factors

1) Orthodontic Appliances

a) Fixed versus removable

b) Begg versus edgewise

c) Magnets

d) Inter-maxillary elastics

2) Extraction versus non-extraction

3) Serial extractions

4) Other appliances

5) Types of orthodontic tooth movement

6) Orthodontic force

7) Continuous versus intermittent force

8) Jiggling and occlusal trauma

9) The extent of tooth movement

(3)Biologic and Mechanical Factors:-

1) Treatment duration

2) Relapse

3) Root resorption after appliance removal

(4)Other Considerations:-

1) Teeth vitality

2) Loss of crestal bone and tooth stability.

\section{Influence of Orthodontic Force on Root Resorption as Studied by Different Authors [Table 1]}

Table 1. Influence of Orthodontic Force on Root Resorption as Studied by Different Authors.

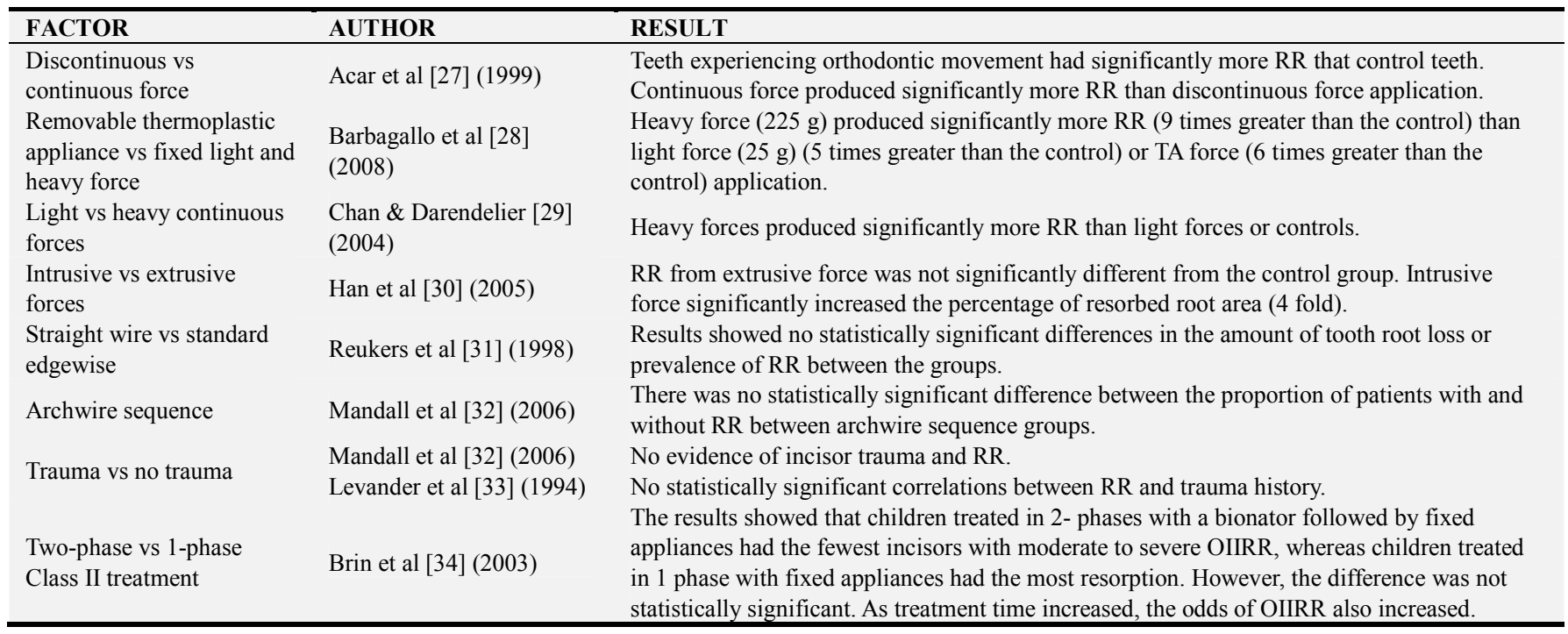




\begin{tabular}{lll}
\hline FACTOR & AUTHOR & RESULT \\
\hline $\begin{array}{l}\text { Self-ligating vs } \\
\text { conventional orthodontic } \\
\text { bracket systems }\end{array}$ & Scott et al [35] (2008) & $\begin{array}{l}\text { The results showed that mandibular incisor RR was not statistically different between the two } \\
\text { systems. }\end{array}$ \\
\hline
\end{tabular}

\section{Diagnosis}

Progressive intra-oral periapical radiographs (IOPAR) still form the major investigative method used to identify mid-treatment root resorption. Multiple grading systems and scoring criteria exist for assessing the resorptive process. [22-25] Severe ARR is defined as a shortening that is more than $4 \mathrm{~mm}$ or one-third of the root length and is observed in $1 \%-5 \%$ of teeth. [36] Histological research indicates an extremely high (more than 90\%) occurrence of root resorption that is caused by orthodontic forces. However, radiological incidence is lower than histological incidence. [37] In a study by Marques et al, [38] the incidence of severe ARR of the incisors after orthodontic treatment was found to be $14.5 \%$. The most commonly used diagnostic techniques are panoramic or periapical radiography. Results show that ARR after orthodontic treatment is underestimated when evaluated with panoramic radiography. Contemporary digital imaging tools such as cone beam computed tomography (CBCT) with reduced radiation dose and high accuracy, have been critical for the purpose of identification. [39] In a recent study by Dudic et al. [40] which compared panoramic radiography with cone beam computed tomography (CBCT), significant differences were found between the two methods: $56.5 \%$ and $31 \%$ of the teeth displayed no resorption in panoramic radiography and $\mathrm{CBCT}$, respectively. Duracket al. [41] compared IOPAR and CBCT for the detection of resorption craters and concluded that IOPAR carries inherent limitations and shortcomings. A detailed study by Sherrard et al [42] concluded that IOPAR evaluation could lead to an underestimation of root length by an average of $2.6 \mathrm{~mm}$ while a CBCT discrepancy is of the order of $0.3 \mathrm{~mm}$, making it the assessment tool of choice. The main problems of CBCT usage are the associated increased radiation dose, cost and ethical issues. Estrela $C$ et al [43] explored the presence of dentine sialoprotein (DSP), dentinephosphoprotein (DPP) \& dentine matrix protein1(DMP-1) in the GCF and it was concluded that the use of DSP and DPP as biomarkers was a suitable alternative for monitoring root resorption during orthodontic tooth movement.

\section{Repair of Root Resorption}

Active orthodontic forces are believed to have an important role in the continuity of root resorption; therefore, the repair process begins after the cessation of orthodontic force or decrease in the magnitude of the force at a certain level. The repair is first observed around the resorption lacunae. This process shows similarity to the early cementogenesis during the development of the teeth.[44]
Resorption lacunae are recovered with the accumulation of new cementum and formation of a new periodontal ligamentum. [45] Owmann-Moll et al[46] stated that the possible repair level in resorption cavities that can be histologically observed can be summarized as follows:

(1)Partial Repair: Part of the surface of the resorption cavity is covered with reparative cementum (cellular or acellular cementum).

(2)Functional Repair: The total surface of the resorption cavity is covered with reparative cementum without the re-establishment of the original root contour (cellular cementum).

(3)Anatomic Repair: The total surface of the resorption cavity is covered with reparative cementum to an extent such that the original root contour is reestablished.

Cheng et al. $[47,48]$ reported that it takes at least 8 weeks of rest for anatomic repair to occur while the partial and functional repair processes predominate during the first 4-6 weeks. The resorption continued for 4 weeks after the stop of orthodontic force. After 4-week light force application followed by 4-week retention, there was continuous and regular repair. It was concluded that a minimum of 4 weeks rest is essential for the initiation of the repair process.

\section{Adjunctive Approaches for the Repair Process}

Many approaches have been demonstrated to reduce the rate of root resorption during orthodontic treatment which includes drugs, hormones, application of low intensity pulsed ultrasound, etc. The drugs which have been administered as potent bone resorption inhibitors include bisphosphonates. The anti-inflammatory properties of tetracycline and NSAIDs have also been noted to reduce root resorption. Studies have been published describing anti-inflammatory properties of tetracycline (and their chemically modified analogues) unrelated to their antimicrobial effect. A significant reduction in the number of mononucleated cells on the root surface was observed. Such cells have been related to EARR. [49] Thus, the administration of anti-inflammatory drugs might suppress root resorption induced by orthodontic therapy. Hormones which have a positive effect on resorption include L-thyroxine and corticosteroids due to its dual activation of parathormone and bone remodelling resulting in less stress on the root apex. Among them, L-thyroxine has been shown to have an inhibitory effect and clinical application has been attempted. [50] Similar effects have been shown for prednisolone in rats, in which low doses of corticosteroids during orthodontic treatment decrease root resorption. [51] Most of these research data are obtained from either animal experiments or by incidental observation of patients consuming these drugs. This 
creates uncertainty related to the clinical applicability of pharmacological programmes solely for the purpose of suppressing the root resorptive process. Considering the unfavourable effects that pharmacology might have in other systems, a rest period of at least 8 weeks is considered the best option, if mid-treatment root resorption is diagnosed.

\section{Conclusion}

Apical root resorption is a common sequel of orthodontic treatment. A proper medical history, an assessment of predisposing factors, a radiographic evaluation for alterations in root morphology and careful planning and execution of orthodontic mechanics may reduce the incidence of root resorption to an extent. A mid-treatment radiographic evaluation can identify teeth at risk and can indicate the need for an adequate rest period so that functional or anatomic repair might be promoted. Root resorption may compromise the continued existence and functional capacity of the affected tooth, depending on its magnitude. However, the process of root resorption during orthodontic treatment is usually smooth and stops when the force is removed.

\section{References}

[1] Ottolengui R. The physiological and pathological resorption of tooth roots. Item of Interest 1914; 36: 332-62.

[2] Ketcham AH. A preliminary report of an investigation of apical root resorption of permanent teeth. Int J Orthod 1927; 13: 115-27.

[3] Ketcham AH. A radiographic study of orthodontic tooth movement: A preliminary report. J Am Dent Assoc 1927; 14: $1577-596$.

[4] Ketcham AH. A progress report of an investigation of apical root resorption of vital permanent teeth, Int J Orthod 1929; 15: 310-28.

[5] Mohandesan H, Ravanmehr H, Valaei N. A radiographic analysis of external apical root resorption of maxillary incisors during active orthodontic treatment. Eur J Orthod 2007; 29 (2): 134-9.

[6] Weltman B, Vig KW, Fields HW, Shanker S, Kaizar EE. Root resorption associated with orthodontic tooth movement: A systematic review. Am J Orthod Dentofacial Orthop 2010; 137 (4): 462-76.

[7] Harris EF, Robinson QC, Woods MA. An analysis of causes of apical root resorption in patients not treated orthodontically. Quintessence Int 1993; 24 (6): 417-28.

[8] Killiany DM. Root resorption caused by orthodontic treatment: An evidence-based review of literature. Semin Orthod 1999; 5 (2): 128-33.

[9] Lee KS, Straja SR, Tuncay OC. Perceived long-term prognosis of teeth with orthodontically resorbed roots. Orthod Craniofac Res 2003; 6 (3): 177-91.

[10] Healey D. Root resorption. 2004. Available from: http://www.orthodontists.org.nz/root_resorption.htm.

[11] Levander E, Malmgren O, Stenback K. Apical root resorption during orthodontic treatment of patients with multiple aplasia: A study of maxillary incisors. Eur J Orthod 1998; 20: 427-34.

[12] Harry MR, Sims MR. Root resorption in bicuspid intrusion. A scanning electron microscope study. Angle Orthod 1982; 52: 235-58.

[13] Brezniak N, Wasserstein A. Orthodontically induced inflammatory root resorption. Part I: The basic science aspects. Angle Orthod 2002; 72: 175-9.

[14] Brudvik P, Rygh P. Multi-nucleated cells remove the main hyalinized tissue and start resorption of adjacent root surfaces. Eur J Orthod 1994; 16: 265-73.

[15] Blaushild N, Michaeli Y, Steigman S. Histomorphometric study of the periodontal vasculature of the rat incisor. J Dent Res 1992; 71: 1908-12.

[16] Chutimanutskul W, Ali Darendeliler M, Shen G, Petocz P, Swain M. Changes in the physical properties of human premolar cementum after application of 4 weeks of controlled orthodontic forces. Eur J Orthod 2006; 28: 313-18.

[17] Abass KS, Hartsfield JK. Orthodontics and External Apical Root Resorption. Semin Orthod 2007; 13: 246-56.

[18] Shafer, Hine, Levy. A textbook of oral pathology. Regressive alterations of the teeth. Fourth edition. 1999: 318-39.

[19] Andreasen J O. Luxation of permanent teeth due to trauma. A clinical and radiographic follow-up study of 189 injured teeth. Scand J Dent Res 1970; 78: 273-86.

[20] Wiliam R. Proffit with Henry W. Fields, Jr.: Contemporary Orthodontics. The biologic basis of orthodontic therapy. Third edition 2001: 296-325.

[21] Fuss Z, Tsesis I, Lin S. Root resorption-diagnosis, classification, treatment choice based on stimulation factors. Dental traumatology 2003; 19: 175-82.

[22] De Shields RW. A study of root resorption in treated class II Division I malocclusion. Angle Orthod 1969; 39: 231-45.

[23] Malmgren O, Goldson L, Hill C, Orwin A, Petrini L, Lundberg M. Root resorption after orthodontic treatment of traumatized teeth. Am J Orthod1982; 82: 487-91.

[24] Levander E, Malmgren O, Stenback K. Apical root resorption during orthodontic treatment of patients with multiple aplasia: a study of maxillary incisors. Eur J Orthod. 1998; 20 (4): 427-34.

[25] Remington, Joondeph, Årtun, Riedel, and Chapko. Long-term evaluation of root resorption during orthodontic treatment. Am J Orthod Dentofac Orthop 1989; 96: 43-6.

[26] Naphtali Brezniak, Atalia Wasserstein. Root resorption after orthodontic treatment: part-2, literature review. Am J Orthod Dentofac Orthop 1993; 104: 138-146.

[27] Acar A, Canyurek U, Kocaaga M, Erverdi N. Continuous vs. discontinuous force application and root resorption. Angle Orthod 1999; 69: 159-63.

[28] Barbagallo LJ, Jones AS, Petocz P, Darendeliler MA. Physical properties of root cementum: part 10. Comparison of the effects of invisible removable thermoplastic appliances with light and heavy orthodontic forces on premolar cementum. A microcomputed- tomography study. Am J Orthod Dentofacial Orthop 2008; 133: 218-27. 
[29] Chan EKM, Darendeliler MA. Exploring the third dimension in root resorption. Orthod Craniofacial Res 2004; 7: 64-70.

[30] Han G, Huang S, Von den Hoff JW, Zeng X, KuijpersJagtman AM. Root resorption after orthodontic intrusion and extrusion: an intraindividual study. Angle Orthod 2005; 75: 912-8.

[31] Reukers E, Sanderink G, Kuijpers-Jagtman AM, van't Hof M. Assessment of apical root resorption using digital reconstruction. Dentomaxillofac Radiol 1998; 27: 25-9.

[32] Mandall N, Lowe C, Worthington H, Sandler J, Derwent S, Abdi- Oskouei M, et al. Which orthodontic archwire sequence? A randomized clinical trial. Eur J Orthod 2006; 28: 561-6.

[33] Levander E, Malmgren O, Eliasson S. Evaluation of root resorption in relation to two orthodontic treatment regimes. A clinical experimental study. Eur J Orthod 1994; 16: 223-8.

[34] Brin I, Tulloch JFC, Koroluk L, Philips C. External apical root resorption in Class II malocclusion: a retrospective review of 1- versus 2-phase treatment. Am J Orthod Dentofacial Orthop 2003; 124: 151-6.

[35] Scott P, DiBiase AT, Sherriff M, Cobourne MT. Alignment efficiency of Damon3 self-ligating and conventional orthodontic bracket systems: a randomized clinical trial. Am J Orthod Dentofacial Orthop 2008; 134: 470.e1-8.

[36] Weltman B, Vig KW, Fields HW, Shanker S, Kaizar EE. Root resorption associated with orthodontic tooth movement: A systematic review. Am J Orthod Dentofacial Orthop 2010; 137: 462-76.

[37] Kokich VG. Orthodontic and non-orthodontic root resorption: Their impact on clinical dental practice. J Dent Educ 2008; 72: 895-902.

[38] Marques LS, Ramos-Jorge ML, Rey AC, Armond MC, Ruellas AC. Severe root resorption in orthodontic patients treated with the edgewise method: Prevalence and predictive factors. Am J Orthod Dentofacial Orthop 2010; 137: 384-8.

[39] Krishnan V. Critical issues concerning root resorption: A contemporary review: World. J Orthod 2005; 6: 30-40.

[40] Dudic A, Giannopoulou C, Leuzinger M, Kiliaridis S. Detection of apical root resorption aft er orthodontic treatment by using panoramic radiography and cone-beam computed tomography of super-high resolution. Am J Orthod Dentofacial Orthop 2009; 135: 434-7.
[41] Durack C, Patel S, Davies J, Wilson R, Manocci F. Diagnostic /accuracy of small volume cone beam computed tomography and intra oral periapical radiography for the detection of simulated external inflammatory root resorption. Int Endod $\mathrm{J}$ 2011; 44: 136-47.

[42] Sherrard JF, Rossouw EP, Benson BW, Carrillo R, Buschang $\mathrm{PH}$. Accurac and reliability of tooth and root lengths measured on cone-beam computed tomographs. Am J Orthod Dentofac Orthop 2010; 137: 100-08.

[43] Estrela C, Bueno MR, De Alencar AH, Mattar R, ValladaresNeto J, Azevedo BC, De Araújo Estrela CR. Method to evaluate inflammatory root resorption by using cone beam computed tomography. J Endod 2009; 35: 1491-7.

[44] Brudvik P, Rygh P. Transition and determinants of orthodontic root resorption-repair sequence. Eur J Orthod 1995; 17: 177-88.

[45] Langford SR, Sims MR. Root surface resorption, repair, and periodontal attachment following rapid maxillary expansion in man. Am J Orthod 1982; 81: 108-15.

[46] Owman-Moll P, Kurol J, Lundgren D. Repair of orthodontically induced root resorption in adolescents. Angle Orthod 1995; 65: 403-8.

[47] Cheng LL, Turk T, Elekdağ-Türk S, Jones AS, Petocz P, Darendeliler MA. Physical properties of root cementum: Part 13. Repair of root resorption 4 and 8 weeks after the application of continuous light and heavy forces for 4 weeks: a microcomputed-tomography study. Am J Orthod Dentofacial Orthop 2009; 136: 320.e321-310.

[48] Cheng LL, Turk T, Elekdag-Turk S, Jones AS, Yu Y, Darendeliler MA. repair of root resorption 4 and 8 weeks after application of continuous and heavy forces on premolars for 4 weeks: a histologic study. Am J Orthod Dentofac Orthop 2010; 138: 727-34.

[49] Mavragani M, Brudvik P, Selvig KA. Orthodontically induced root and alveolar bone resorption: inhibitory effect of systemic doxycycline administration in rats. Eur J Orthod. 2005; 27 (3): 215-25.

[50] Shirazi M, Dehpour AR, Jafari F. The effect of thyroid hormone on orthodontic tooth movement in rats. J Clin Pediatr Dent. 1999; 23 (3): 259-64.

[51] Ong CK, Walsh LJ, Harbrow D, Taverne AA, Symons AL. Orthodontic tooth movement in the prednisolone-treated rat. Angle Orthod; 70 (2): 118-25. 